\title{
Brief-ANT as a tool for measuring the influence of roadside advertisements content on the drivers' attentional processes
}

\author{
Anna Olejniczak-Serowiec ${ }^{1}$, $^{*}$,Norbert Maliszewski ${ }^{2}$, and Justyna Harasimczuk ${ }^{2}$ \\ ${ }^{1}$ University of Warsaw, Faculty of Psychology, Stawki 5/7, 00-183 Warsaw, Poland \\ ${ }^{2}$ Kardinal Stefan Wyszynski University, Institute of Psychology, Wóycickiego 1/3 b. 14, 01-938 \\ Warsaw, Poland
}

\begin{abstract}
The question of roadside advertisement's influence on road safety is complex and multi-faceted. The list of advertisements characteristics which may play significant role for road safety includes: the size, colours, shape, luminance, contrast, localization, and many more. One of the aspects is advertisement's content. Advertising industry uses emotional and cognitive mechanisms which are likely to engage the addressees' attention and therefore make the brand/product more salient for their minds. As far as such a strategy might be effective for advertisers, it may be dangerous for road safety, when used in roadside advertisement. Cognitive, especially attentional, resources play key role in vehicle driving, which requires constant maintenance of situational awareness. Attention distraction, both visual and cognitive, is a proven safety-decreasing factor in vehicle driving. A method for measuring the influence of different advertisement content on attentional resources management - a short, version of the ANT, Brief-ANT, was developed. The results of a nationwide study conducted, revealed that reaction time in Brief-ANT differed significantly depending on the type of content used as the fixation cue, which leads us to a conclusion that Brief-ANT might be a good measure of the content's influence on attentional resources management.
\end{abstract}

\section{Introduction}

The question of roadside advertisement's influence on road safety is complex and multifaceted. The list of advertisements characteristics which may play significant role for road safety includes: the size, colours, shape, luminance, contrast, localization, and many more. One of the aspects is advertisement's content.

The advertisement's content itself is also a complex construct. The particular idea might be expressed both verbally and nonverbally (i.e., via the use of colours, shapes, and pictograms). Whichever technique is used, the aim of advertisement is to catch addressee's attention, and subsequently, engage him in processing its content in order to finally increase the product's or brand's salience in his mind [1]. To achieve this goal, advertisers use

\footnotetext{
* Corresponding author: anna.olejniczak@psych.uw.edu.pl
} 
various mechanisms. Although the list below might be incomplete, it covers most of the mechanisms commonly observed in roadside advertising in Poland, moreover, many of them are considered as dangerous when used in roadside advertising.

- Slogans - text-based advertising, which might be either direct or incorporate more ambiguous or inexplicit literary figures (e.g., metaphors, ambiguity) [2];

- Sexual appeals [3];

- Negative emotions (e.g., fear, sadness, distaste) [4-6];

- Positive emotions (e.g., pleasure, drollery, tenderness) [7];

- Teasers - advertising in a form of a planned campaign consisting of two expositions: the first one containing some obscurity, and the second - suspended in time - dissolving the obscurity [8];

- Colour intensity and contrast use;

- Picture complexity, i.e., the number of pictograms used in advertising [9];

- Unusual form.

As mentioned above, advertising is often aimed at catching addressee's attention, which in the context of roadside advertisement might mean: driver's attention. Meanwhile, cognitive, especially attentional, resources play key role in vehicle driving, which requires constant maintenance of situational awareness. Attention distraction, both visual and cognitive, is a proven safety-decreasing factor in vehicle driving [10-12].

The content of roadside billboards can influence the driver's attention not only during the exposition (i.e., while looking at the advertisement) but also, when his eyes are back on the road [13]. In such a situation, the driver is seemingly looking on the road, but because he is still processing the information seen before, his attentional resources are depleted [14]. Therefore, it seems useful to verify the effect of different types of roadside advertising content on driving safety in terms of attentional processing.

Posner defines attention as a system, which directs information flow and controls (i.e., prioritizes) information validity [13]. According to his theory, attentional functioning is based on three systems responsible for three functions: altering, orienting, and executive control. Attention Networks Test is a behavioural method designed to measure the activity of the three systems [15]. The task consists of a series of trials, in which the participant's task is to indicate the direction of an arrow used as a so called signal. The arrow might appear in the context of other arrows directed in the same or different direction than the signal (congruent vs. incongruent), it might also appear above or below the fixation point. In the test, reaction time serves as one of the main indicators of attention efficiency. As the purpose of the present project was not to measure the activity of the three systems, but to verify the influence of different types of advertising contents on the processing efficiency of attention, we decided on developing a simple laboratory method for verifying the effect. The method is based on one of the versions of ANT task developed by CRSD (Centre for Research on Safe Driving) [16]. The development of the method, called Brief-ANT, and all implemented modifications are described below.

\section{Method}

\subsection{Participants and procedure}

A sample of 800 Polish drivers were involved in the study, 293 female and 507 male. After corrections for missing data, the sample consisted of 684 drivers: 253 female and 431 male. $15 \%$ (103) of the participants were between 18 and 14 years old, 166 were aged 25-35, 163 fell into the group between 35 and 44 years old, 124 were between 45 and 54, and 128 of the participants were over 54 years old. $66 \%$ of the respondents declared using a car daily, 
and $21 \%$ - at least once a week (the rest of the group declared using a car less frequently). All types of habitats were represented in the sample: villages $(42 \%)$, town up to 100,000 occupants (30\%), towns between 100,000 and 500,000 occupants (18\%), and cities over 500,000 occupants $(10 \%)$.

The study was a nationwide CAWI research in which the participants filled in an online survey consisting of demographic questions and the Brief-ANT. All participants were voluntary respondents recruited by the research panel and were rewarded for handing in the survey with credit points that they could subsequently exchange for rewards. The survey was secured from being reached twice by the same participant.

\subsection{Materials and methods}

Each participant started with a survey including demographic and driving experience related questions. Next, they filled in a Brief-ANT.

The CRSD version of the ANT test consists of 2 blocks of 64 trial sequences each (ordered randomly), organized in the following sequences: 2 (repetitions) $\mathrm{x} 4$ (cue conditions: no cue/centre cue/double cue/spatial cue) x 2 (flanker conditions: congruent vs. incongruent) $\times 2$ (target positions: above or below) x 2 (target directions: right or left). Each trial consists of the following sequence: fixation (presentation time: $400 \mathrm{~ms}$ to $1200 \mathrm{~ms}$ ) -> cue $(100 \mathrm{~ms})->$ fixation $(400 \mathrm{~ms})->$ target $(1500 \mathrm{~ms})->$ mid-trial interval $(3000 \mathrm{~ms})$.

In Brief-ANT, the fixation cue is either an advertisement $(450 \times 300 \mathrm{px})$ or a cross (like in the original; cf. Fig. 1). Presentation time was set constant: $2000 \mathrm{~ms}$ - the assumed safetycritical time for visual attention distraction in many transportation research. Then, the cue followed, but the re-fixation time was shortened to $100 \mathrm{~ms}$. This was done to reduce the time between exposition to the advertisement and reaction. Finally, the target was presented for $1500 \mathrm{~ms}$. To sum up, the Brief-ANT trial consisted of the following sequence: fixation $(2000 \mathrm{~ms})->$ cue $(100 \mathrm{~ms})->$ fixation $(100 \mathrm{~ms})->$ target $(1500 \mathrm{~ms})->$ mid-trial interval $(3000 \mathrm{~ms})$. In order to test the method in online version, a pilot study $(\mathrm{N}=80)$ was conducted.

A)

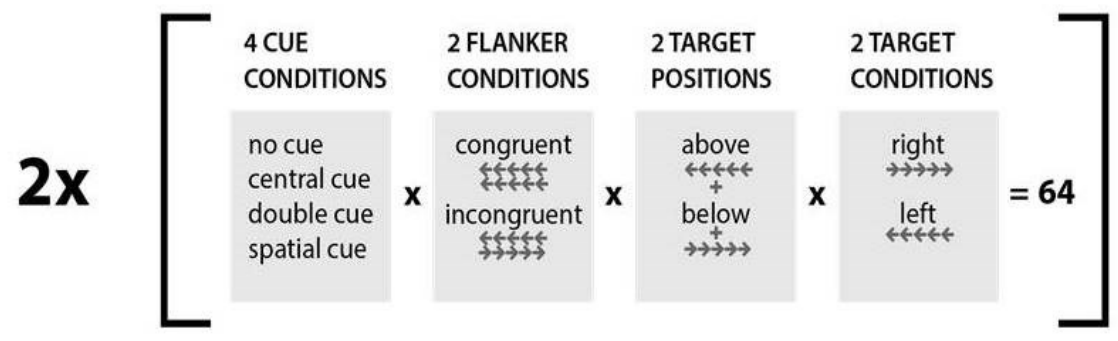

B)

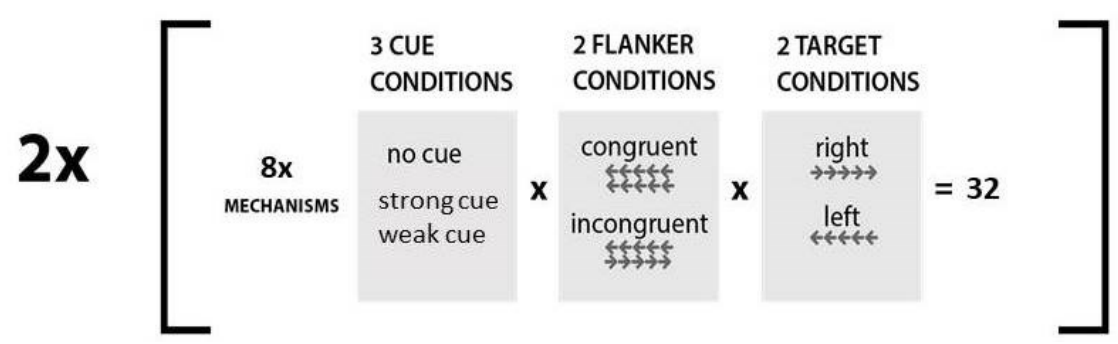

Fig. 1. Diagram comparing Brief-ANT (B) to the original version of ANT (A).

In the present study, different types of advertisement's content referring to the mechanisms described in the Introduction were used. The stimuli consisted of four 
advertisements representing each mechanism, two with high intensity of the cue and two with low intensity of the cue. Consequently, we used:

- 4 sexual advertisements (2 strong - showing naked bodies and 2 weak - showing gentle erotic cues);

- 4 emotionally negative advertisements ( 2 strong - e.g., showing blood and victims, and 2 weak - showing indirect cues about negative events);

- 4 emotionally positive advertisements $(2$ - using humour and 2 - inducing general positive affect);

- 4 picture-based advertisements ( 2 - using multiple pictograms and 2 - simplex);

- 4 text-based advertisements $(2$ - using sort slogans and 2 - conveying the same message in more words);

- 4 colour-based advertisements ( 2 - with intense colours and high contrast, and 2 - with mild colours and low contrast);

- 4 teaser advertisements ( 2 - including obscurity and 2 - resolving it);

- 4 form-based advertisements (2 - in typical form of a rectangular billboard and 2 with exactly the same content shown in a unusual form).

Advertisements within the 'weak-strong' pair used the same stimuli (e.g., model, object) and varied only in the intensity of the cue. The choice of advertisements used in the study was based on the results of pilot studies $(\mathrm{N}=30)$. For each mechanism, ten pairs of advertisements varying with regard to the intensity of the key cue were prepared. The proper study uses pairs for which the pilot study revealed differences in the level of the key mechanism (i.e., sexuality, negative emotions, etc.), but not with regard to other characteristics (e.g., attractiveness). The advertisements were displayed instead of the cue in original ANT version.

The sequence of screens in the original version of ANT and in Brief-ANT is illustrated in figure 2.

A)
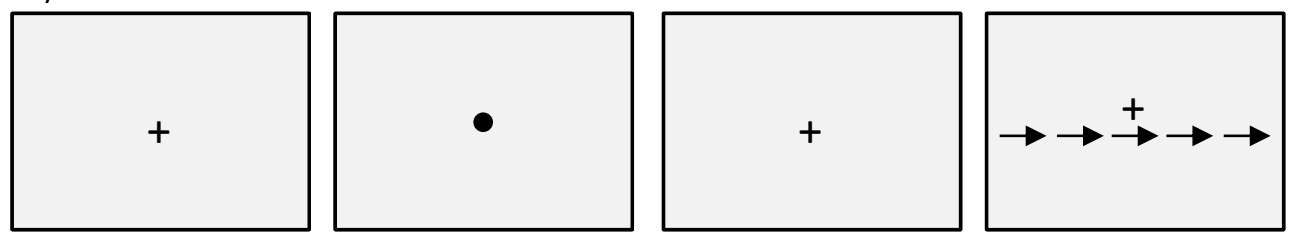

B)
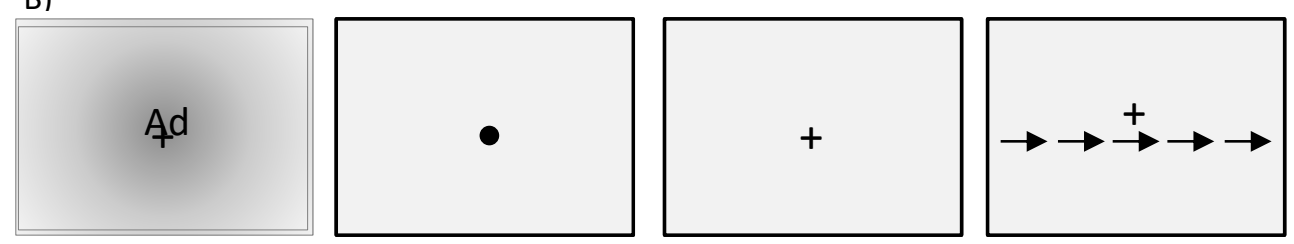

Fig. 2. The sequence of screens in original ANT (A) and in Brief-ANT (B).

\section{Results}

Reaction times with no advertisement-fixation cue were excluded from the following analyses, as they were in general shorter than in the context of exposition to advertisement, which is in line with observations from other ANT-based studies, showing the influence of arousal on reaction times $[17,18]$. 
Reaction times in the context of advertisements with various contents type were analysed with SPSS 23 software. The results of the GLM analysis revealed, that reaction times were different in the context of various content types $F=16.089 ; p<.001 ; \eta^{2}=.023$. Figure 3 illustrates the results of the analysis.

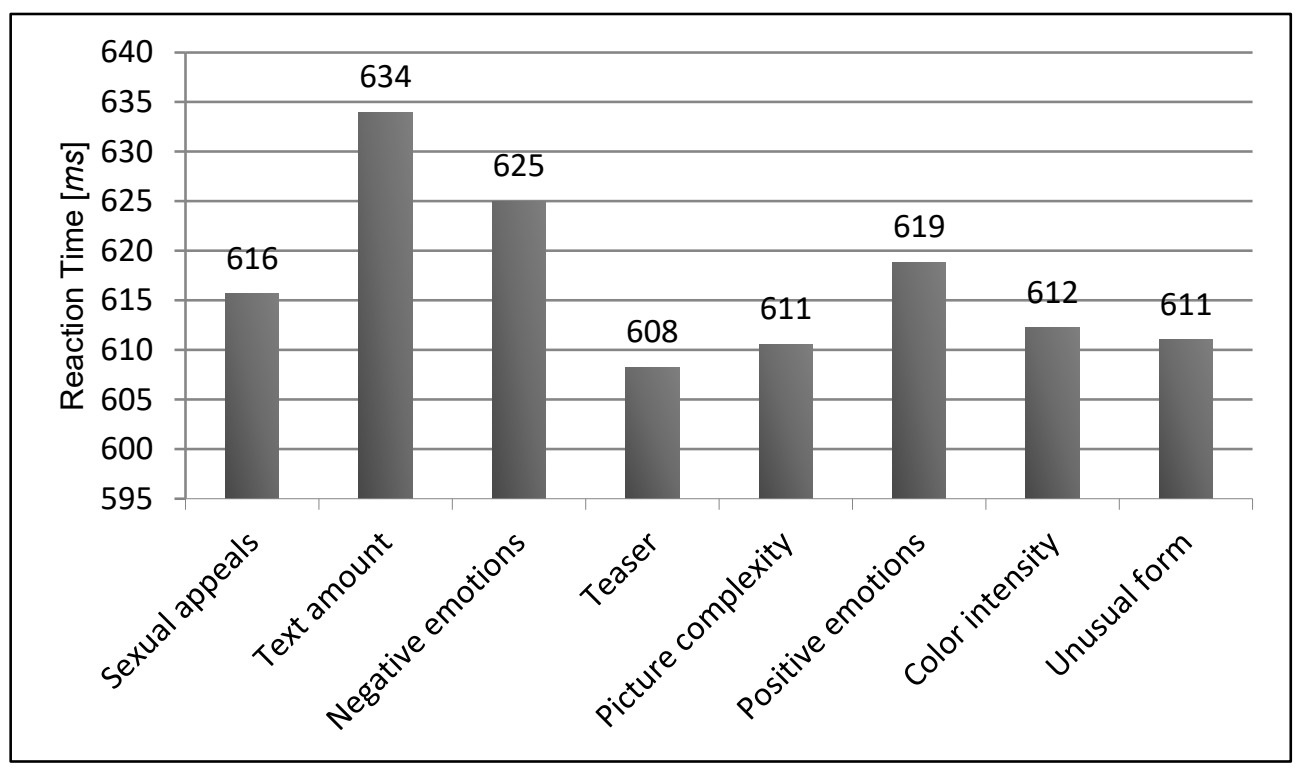

Fig. 3. Reaction times in the context of various advertisment types.

A series of contrast analyses was performed to reveal which reaction times differ significantly from one another. The results of contrast analyses are presented in table 1 .

Table 1. Contrast analyses of reaction times in the context of various advertisments $p$ values.

\begin{tabular}{|c|c|c|c|c|c|c|c|c|}
\hline \multicolumn{2}{|c|}{} & $\mathbf{1 .}$ & $\mathbf{2 .}$ & $\mathbf{3 .}$ & $\mathbf{4 .}$ & $\mathbf{5 .}$ & $\mathbf{6 .}$ & $\mathbf{7 .}$ \\
\hline $\mathbf{1 .}$ & $\begin{array}{c}\text { Sexual } \\
\text { appeals }\end{array}$ & & & & & & & \\
\hline $\mathbf{2 .}$ & $\begin{array}{c}\text { Text } \\
\text { amount }\end{array}$ & $<.001$ & & & & & & \\
\hline 3. & $\begin{array}{c}\text { Negative } \\
\text { emotions }\end{array}$ & .003 & .005 & & & & & \\
\hline 4. & Teaser & .013 & $<.001$ & $<.001$ & & & & \\
\hline $\mathbf{5 .}$ & $\begin{array}{c}\text { Picture } \\
\text { complexity }\end{array}$ & .096 & $<.001$ & $<.001$ & .424 & & & \\
\hline $\mathbf{6 .}$ & $\begin{array}{c}\text { Positive } \\
\text { emotions }\end{array}$ & .292 & $<.001$ & .052 & $<.001$ & .008 & & \\
\hline 7. & $\begin{array}{c}\text { Color } \\
\text { intensity }\end{array}$ & .248 & $<.001$ & $<.001$ & .180 & .590 & .025 & \\
\hline 8. & $\begin{array}{c}\text { Unusual } \\
\text { form }\end{array}$ & .132 & $<.001$ & $<.001$ & .353 & .880 & .009 & .691 \\
\hline
\end{tabular}

In order to verify whether reaction times in the context of advertisements using the same mechanisms but of different intensity, a series of pairwise T-tests was performed. Results of the comparisons are illustrated in figure 4. 


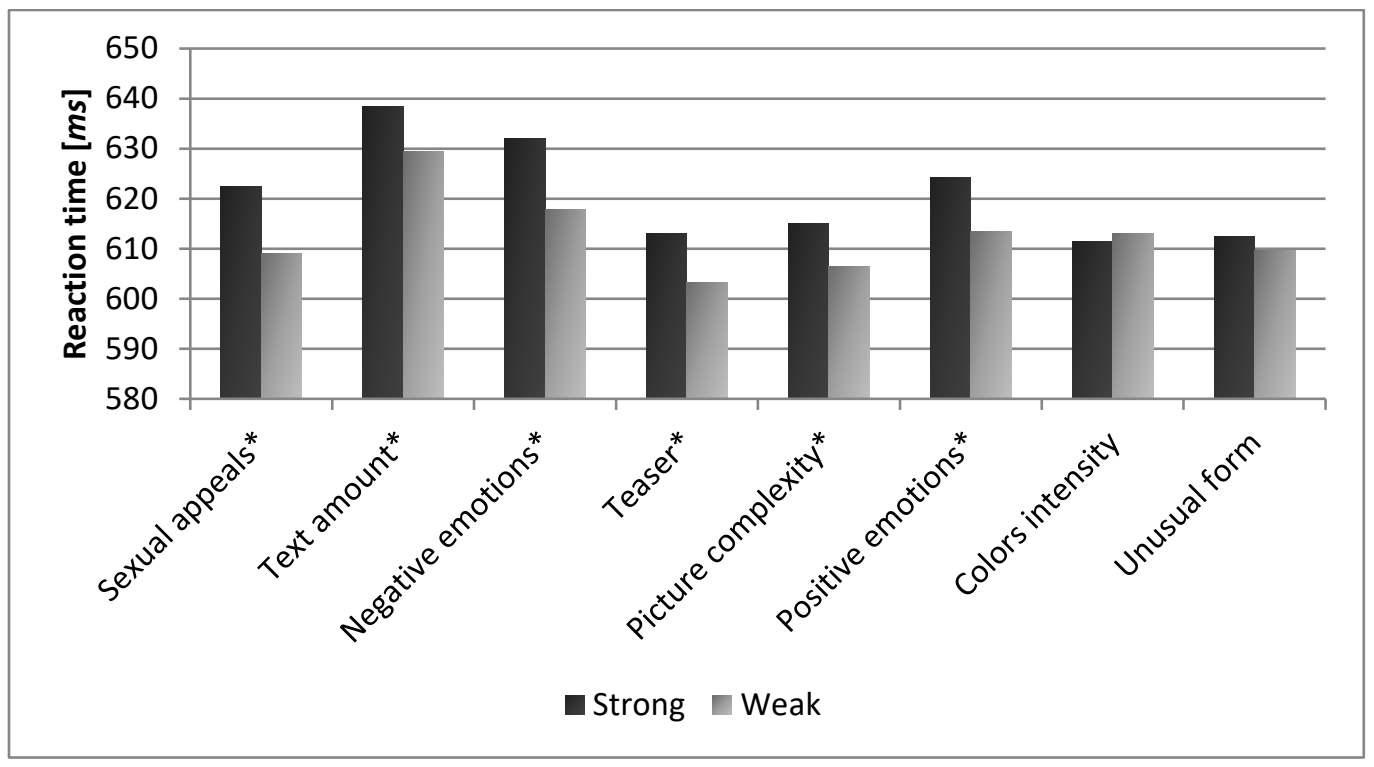

Fig. 4. Pairwise T-tests for Reaction Time [ms] in te context of different intensity of mechanism used. Statistically significant differences are indicated with an asterisk.

\section{Conclusion}

The results of the study reveal that Brief-ANT differentiates the processing efficiency of attention in the context of various cues.

Reaction times observed when advertisements based on different mechanisms were used as a cue differed significantly. The longest reaction time was observed after the exposition of text-based advertisements. Moreover, exposition of longer slogans elicited longer reaction times than did shorter ones.

The next longest reaction times were observed after the exposition to emotion inducing advertisements: negative and positive successively. The difference between those two mechanisms - induced reaction times was nonsignificant, while the reaction times observed after their exposition were significantly longer than after the exposition of any other type of cue (textual advertisements excluded) in case of emotionally negative cues (the differences did not reach the level of statistical significance in case of emotionally positive stimuli). What is more, the intensity of the emotional cue (strongly negative vs. mildly negative, humorous $v s$. generally positive) changed the reaction times observed, i.e., they were longer in case of strongly negative and humorous cues than in the other contexts. Although negative emotional stimuli caused reaction times which differed more significantly from those caused by other mechanisms than did those caused by positive emotional stimuli, they both seem to have similar effect. This might mean that it's the arousal that influences the processing effectiveness of attention, not its' valence.

The fourth longest reaction time was observed in the context of sexually appealing advertisements. Also, reaction times after the exposition of more intense erotic cues were longer than when mildly erotic cues were presented. Such a pattern of results, seems consistent with the thesis expressed in the former paragraph, therefore forming a group of three arousing mechanisms, which may severely influence attentional functioning.

The above considerations seem consistent with observations from other, elsewhere published, studies conducted with the use of driving simulator. We observed that longer slogans resulted in increased variation in maintaining the distance to the vehicle in front in 
the Three Vehicle Platoon Task [19]. Similar effects were observed during the exposition of negative emotion - based advertisements - strongly negative stimuli in roadside advertisements influenced distance maintaining more, than did weak negative stimuli [20]. Moreover, longer advertising slogans used in roadside advertising resulted in longer reaction times in Lane Changing Task, than did shorter ones [21], i.e., when exposed to billboards with longer slogans, it took drivers longer time to change driving lane in reaction to a traffic sign.

Reaction times after exposition to visually more complex stimuli, were also longer than those following simplex stimuli. Such an effect finds confirmation in research on the influence of roadside advertising on driving effectiveness [9].

No differences were observed for two mechanisms: colour intensity and unusual form. As for the latter, the lack of the effect might be due to the computer-based method, which considerably decreases the visibility of form variations, reducing them all to a two dimensional photo displayed on the screen. The former mechanism, possibly needs more in-depth investigation, however, the lack of differences might be a result of the fact, that participants had no other possibility than observe the advertisement, when it was displayed, while colour intensity possibly plays its' role in attention catching, not influencing the attentional processing as such.

Interestingly, the fact that reaction times in Brief-ANT vary depending on the type of cue, seems to confirm the assumption, that using attention-catching mechanisms in advertising influences attentional processes not only during the exposition but also afterwards.

The results of the study lead us to a conclusion that Brief-ANT might be a good measure of the content's influence on attentional resources management and can be useful in the research on the safety-critical characteristics of advertising contents in the context of driving safety.

The research and the preparation of this article were founded by the National Centre for Research and Development and the General Director for National Roads and Motorways (DZP/RID/I33/4/NCBR/2016).

\section{References}

1. G. Zaltman, R. Coulter, Seeing the Voice of the Customer: Metaphor-based Advertising Research, J. Advert. Res. 35 pp. 35-51 (1995)

2. F. Schieber, K. Limrick, R. McCall, A. Beck, Evaluation of the Visual Demands of Digital Billboards Using a Hybrid Driving Simulator, Proc. Hum. Factors Ergon. Soc. Annu. Meet. 58 pp. 2214-2218 (2014). doi:10.1177/1541931214581465

3. D. Richmond, T.P. Hartman, Sex appeal in advertising, J. Advert. Res. 22 (1982)

4. K.L. Higbee, Fifteen years of fear arousal: Research on threat appeals, Psychol. Bull. 72 pp. 426-444 (1969)

5. P.A. Keller, L.G. Block, Inreasing the Persuasiveness of Fear Appeals: The Effect of Arousal and Elaboration, J. Consum. Res. 22 pp. 448-459 (1996)

6. A. Megías, L.L. Di Stasi, A. Maldonado, A. Catena, A. Cándido, Emotion-laden stimuli influence our reactions to traffic lights, Transp. Res. Part F Traffic Psychol. Behav. 22 pp. 96-103 (2014). doi:10.1016/j.trf.2013.09.017

7. T.J. Madden, M.G. Weinberger, Humor in Advertising: A Practitioner View, J. Advert. Res. 24 pp. 23-29 (1984)

8. K. Trehan, G.S. Maan, Teaser Campaigns: An Effective Advertising Execution for Varied Goods, Services and Ideas, J. Mass Commun. Journal. 02 (2012). 
doi:10.4172/2165-7912.1000138

9. Y. Zhang, E. Harris, M. Rogers, D. Kaber, J. Hummer, W. Rasdorf, J. Hu, Driver distraction and performance effects of highway logo sign design, Appl. Ergon. 44 pp. 472-479 (2013). doi:10.1016/j.apergo.2012.10.009

10. J. Engström, E. Johansson, J. Östlund, Effects of visual and cognitive load in real and simulated motorway driving, Transp. Res. Part F Traffic Psychol. Behav. 8 pp. 97120 (2005). doi:10.1016/j.trf.2005.04.012

11. M. Kruszewski, M. Niezgoda, T. Kmiński, A. Matysiak, Wyniki pilotażowego badania wpływu obciążenia poznawczego zadaniem dodatkowym na kierowców, wykonywanego na symulatorze jazdy AS1200-6, Pr. Nauk. Politech. Warsz. - Transp. 116 pp. 155-167 (2017)

12. D.A. Redelmeier, R.J. Tibshirani, Association between Cellular-Telephone Calls and Motor Vehicle Collisions, N. Engl. J. Med. 336 pp. 453-458 (1997). doi:10.1056/NEJM199702133360701

13. M.I. Posner, S.E. Petersen, The Attention System of the Human Brain, Annu. Rev. Neurosci. 13 pp. 25-42 (1990). doi:10.1146/annurev.ne.13.030190.000325

14. D. Kahneman, Attention and Effort. Englewood Cliffs: Prentice-Hall inc (1973). doi:10.2307/1421603

15. J. Fan, B.D. McCandliss, T. Sommer, A. Raz, M.I. Posner, Testing the Efficiency and Independence of Attentional Networks, J. Cogn. Neurosci. 14 pp. 340-347 (2002). doi:10.1162/089892902317361886

16. B. Weaver, M. Bédard, J. McAuliffe, Evaluation of a 10-minute Version of the Attention Network Test, Clin. Neuropsychol. 27 pp. 1281-1299 (2013). doi:10.1080/13854046.2013.851741

17. F. Techer, C. Jallais, A. Fort, Y. Corson, Assessing the Impact of Anger State on the Three Attentional Networks with the ANT-I, Emotion. 15 pp. 276-280 (2015). doi:10.1037/emo0000028

18. J. Moriya, Y. Tanno, Dysfunction of attentional networks for non-emotional processing in negative affect, Cogn. Emot. 23 pp. 1090-1105 (2009). doi:10.1080/02699930802335018

19. J. Harasimczuk, N. Maliszewski, A. Olejniczak-Serowiec, Are longer advertising slogans more dangerous? Influence of the amount of information in advertisement on the attention and motor behavior of the drivers, Curr. Psychol. pp. 1-13 (2018). doi:10.1007/s12144-018-9955-y

20. N. Maliszewski, A. Olejniczak-Serowiec, J. Harasimczuk, Sexual appeal in roadside advertisement and its influence on drivers behavior (under review), (n.d.)

21. N. Maliszewski, J. Harasimczuk, A. Olejniczak-Serowiec, Social advertising with a high intensity of negative emotions may be a threat to drivers (under review), (n.d.) 